\title{
The Possibility Survey of Applying CBI to College English Teaching in WTU
}

\author{
Qunsheng Ke \\ School of Foreign Languages, Wuhan Textile University, Wuhan, China \\ Xiaoying Chen \\ Taihe High School, Ezhou, Hubei, China
}

\begin{abstract}
Content-Based Instruction (CBI) has been found to be an effective approach to teaching English as foreign language (EFL), in which the EFL students can develop their linguistic ability, as well as gain access to meaningful content knowledge. This study covers a questionnaire survey in part of Grade 2010 and 2011 Non-English majors in Wuhan Textile University (WTU); it is about the possibility of applying CBI to College English teaching in WTU. It's been found out that, most of the students are very willing to accept this concept in the curriculum instruction, and they also think it is feasible, though a small number of students do not understand it thoroughly owing to brief introduction to $\mathrm{CBI}$ in the front of the questionnaire.
\end{abstract}

Index Terms-CBI, college English teaching, questionnaire survey, possibility

\section{INTRODUCTION}

The English level of university students in China is not all good enough; some of them are even shy to open their mouths to speak English. The traditional college English grammar-translation teaching mode in China is inefficient. Recently Content-based Instruction (CBI) mode gained remarkable success in America, soon in Europe, Southeast Asia, Australia and other countries and regions.

CBI has been defined, by Richards \& Rodgers, as "the teaching of content or information in the language being learned with little or no direct or explicit effort to teach the language itself separately from the content being taught" (2001: p.204). This teaching approach is considered by many researchers an effective and realistic teaching method in terms of combining language and content learning.

In recent years, some Chinese EFL educators began to prove into CBI and practice CBI in the classroom. Luo (2006) believes CBI countries and the societies require the foreign language teaching raising the foreign language learners' comprehensive ability and training complex language talent requirements. Yu (2005) believes foreign language teaching complied with the request, for domestic magnificent and victorious foreign language teaching reform added new content. In the recent years, Dalian University of Foreign Languages has opened the CBI courses for English majors at the basic stage, Shanghai Jiao Tong University, Suzhou University and so on, also practiced the CBI mode based on the CBI courses.

Our university (Wuhan Textile University) has made some preparations for some EFL teaching reform. As an English teacher, I am thinking whether it is possible to apply CBI concept to the college English teaching in our university. If the survey is positive, I will send a College English teaching project to the authorities.

\section{CONTENT-BASED INSTRUCTION}

Content-based Instruction (CBI) is a significant approach in language education (Brinton, Snow \& Wesche, 1989). $\mathrm{CBI}$ is designed to provide second-language or foreign language learners instruction in content and language. It integrates language instruction with content instruction, but allows the content to determine the nature and order of the linguistic syllabus. CBI in language teaching is not new; however, as a formal approach with theoretical underpinnings, in the past 10 years it has gained popularity, particularly in ESL environments (Snow \& Brinton, 1989). The relationship between the content and the language in CBI, and the extent to which the content and language are conceived of as opposite ends of a methodological continuum, is the subject of some debate. Grebe and Stroller (1997) locate what they see as strong pedagogical support for CBI in second language acquisition research, training studies, educational and cognitive psychology and program outcomes. Brinton et al. argue that CBI provides a meaningful context for language development, as it not only builds on students' previous learning experiences and current needs and interests, but also takes account of the eventual purpose for which students need the language (1989).

CBI is supported by Kristen's Monitor Model: "if students are given comprehensible input, it is less difficult to learn the target language, and as a result, they can acquire it". He emphasized ways of decreasing learner anxiety, such as providing interesting texts as well as meaningful activities, which are comprehensible to learners, and CBI has the following essential features: "learning a language through academic content, engaging in activities, developing 
proficiency in academic discourse, fostering the development of effective learning strategies" (1982, pp.20-30). Thus, this methodology puts emphasis on learning about something rather than learning about language. There are several issues which teachers should consider for an effective use of Content-based EFL instruction, including types, syllabus design, and materials of CBI (Davies, 2006).

CBI teaching mode originated in the form of "immersion program" in Canada in 1965. And it gained popularity thanks to its remarkable success. CBI has been practiced in ESL/EFL teaching in the world since the 1870s, the United States, Canada, Japan, Great Britain, India, Singapore, Germany and other countries (Adamson, 1993). And these countries have policy and laws and regulations supporting the CBI teaching mode, and they are picking CBI teaching mode having been many successful experiences. Particularly, CBI can be used for different academic field of applied research, such as literature, movie, culture and civilization.

"Higher Education under the environment of CBI teaching mode", in which CBI is discussed in higher education settings, edited by Professor JoAnn Crandall and Bauman, introduces the CBI English teaching situation. It is one of case study series of Dr. Jill Burton of TESOL teaching practice of South Australian University. In recent years a total of eleven teaching cases about the CBI on English teaching pattern of research results had been recorded in it (Stryker, S. \& Leaver, B. 1997).

In China, some EFL educators began to dig into CBI and practice CBI in the classroom since 1990. Luo (2006) believes CBI teaching raising the foreign language learners' comprehensive ability and training complex language talent requirements. Yu finds (2005) foreign language teaching complied with the request, for domestic magnificent and victorious foreign language teaching reform added new content. However, the teaching theory in our experience, introducing recommended, short-term silence, the new emphasis on and began to practice application process, and for the CBI study and practice of the application has gradually aroused the attention of the Chinese foreign language experts $(\mathrm{Li}, 2002)$.

Cai (2002) found that the relevant domestic research on CBI theory was late by nearly 10 years compared with that in the foreign countries. Shu and Zhuang (1996) thought that the relevant domestic research of the teaching method is different from foreign teaching development. The theory of CBI mentioned first in our country, afterward the practice in education.

Wang Shixian first introduced the basic concept and the original model of CBI into China in 1994, discussing the possibility of applying CBI to Chinese foreign language teaching; Cai (2002) provides theoretical support and practical strategies from the teaching mode for the second language teaching model; Dai \& Lv (2004) and Yuan (2006) make a comprehensive discussion on CBI as foreign language teaching.

Recently a lot of articles about the CBI teaching idea emerged in China. Since 2005 the experts published their all kinds of foreign language teaching modes in teaching practices, or test CBI mode and method of the report. Yuan (2008) found that implementation of the teaching content had a good influence on the students' English learning motivation and strategies, and made students use English more actively. In addition, some researchers demonstrated interest in the application of CBI to English teaching in China (Zhang, 2002).

Since the establishment of Bilingual research centers, Bilingual curriculum materials research center, and the Bilingual education research center, East China Normal University has held the nationwide conference regularly (Yuan, 2006). And dozens of articles about CBI have been published in various foreign journals.

Recently, Dalian University of Foreign Languages has opened the CBI model system courses for English majors at the basic stage. Some key universities, such as Shanghai Jiao Tong University, Beijing University, Tsinghua University, Zhejiang University, East China Normal University, South China Normal University, Beijing Normal University, Suzhou University, also opened the CBI mode program based on the CBI courses (Li, 2009).

\section{SURVEY}

200 students from thirteen schools in WTU are chosen to do a questionnaire on the possibility of applying CBI to our college English teaching in our university. Actually, 194 valid questionnaires are received. All of them are non-English majors of freshman and sophomores, of whom are 81 girls and 113 boys, 74 of liberal arts and 120 of engineering. They have studied English for at least 6 years. One of their present aims in English is to pass the College English Test Band 4 or Band 6(CET-4 or CET-6).

42 participants are from School of Mechanical Engineering and Automation, of whom are 28 sophomores and 14 freshmen, 12 girls and 30 boys. 50 are from School of Management, in which, 28 are sophomores and 22 are freshmen, 28 girls and 22 boys. 9 participants from School of Economics, in which, 4 are sophomores and 5 are freshmen, 6 girls and 3 boys. 30 are from School of Chemistry and Chemical Engineering, 5 sophomores and 25 freshmen, 3 girls and 27 boys. Among the 10 participants from School of Accountancy, 8 are sophomores and 2 freshmen, 8 girls and 2 boys. There are 15 students from School of Mathematics and Computer Science, 5 sophomores and 10 freshmen, 6 girls and 9 boys. There are 9 participants from School of Electronic and Electrical Engineering, of whom are 8 sophomores and 1 freshman, 2 girls and 7 boys. 10 students are from School of Textile Science and engineering, 7 sophomores and 3 freshmen, 6 girls and 4 boys. There are 3 from School of Environmental Engineering, sophomores, 1 girl and 2 boys. 9 are from School of Textile Science and Engineering, in which, 2 are sophomores and 7 are freshmen, 3 girls and 6 boys. 3 students are from School of Media and Communication, and 2 are sophomores and 1 is freshman. All are girl students. 
4 boys from School of Art and Design are also invited to take part in this survey.

A questionnaire on CBI in order to understand the possibility of applying the CBI teaching mode to our College English curriculum teaching is designed, in Chinese(See Appendix 1), so as to facility the students understanding.

A brief introduction to CBI is printed at the very top of the questionnaire. 10 questions are designed to assess the students' interest on this new teaching mode, and the four choices are arranged from disagreement to absolute agreement. The students make the choices according to their real situation. Among the 10 questions, 2 of them are about personal information, 2 of them are about the level both of the students and teachers, and others are about CBI, such as its function and features.

Among the total of 194 valid questionnaires received, 79 are paper questionnaires and 115 are electronic ones.

I asked my colleagues and friends for help who are the student leaders of School of Mechanical Engineering and Automation and School of Management. When they meet a regular meeting, they had 10 minutes to do the paper questionnaire. It was difficult for some of them to understand what CBI is only by the print description. If any of them had any questions, they were encouraged to ask me immediately. So, I verbally introduced what CBI was, so they could easily understand them. A good understanding would increase the accuracy of their responses. Finally I collected 90 paper questionnaires, but only 79 are valid.

At the same time, I asked my students and friends in our university help me send the electronic questionnaires to their classmates, 110 students, via QQ and email. I have told them those who have filled the paper questionnaires need not fill it again. Four days later, I collected 115 e-questionnaires valid. I sorted out the choices in the 194 questionnaires, took a statistical collection of different categories and of the number of each question (See Appendix 2).

\section{ResUlts AND ANALYSIS}

After all the answers are collected and carefully analyzed, it is found out as the following tables tell.

For the first question: the understanding degree of CBI concept

\begin{tabular}{|l|l|l|l|l|}
\hline Options & A & B & C & D \\
\hline Percentage & $19.6 \%$ & $35.1 \%$ & $38.7 \%$ & $6.7 \%$ \\
\hline
\end{tabular}

According to the above table, we can see that $19.6 \%$ students are not clear about what CBI concept is, $35.1 \%$ students have basic understanding of it, $38.7 \%$ students are clear about it, and $6.7 \%$ students can definitely comprehend it. Survey results show that more than $80 \%$ of the students know CBI concept in different degrees.

Compared the percentage of students who know the concept and the other who are not clear about it, we find that most students can understand the concept. The reason why those students do not know the concept is that there are 62 surveyed students of electronic questionnaires choice A; the electronic questionnaires are filled in by the computer, some of them did not understand what CBI is just by the brief introduction to CBI, however, those students who filled in the paper questionnaires could understand it better, because I can oral explain What CBI is in detail.

(2) Teachers' emphasis in English classes

\begin{tabular}{|l|l|l|l|l|}
\hline Options & A & B & C & D \\
\hline Percentage & $11.3 \%$ & $26.3 \%$ & $56.2 \%$ & $6.2 \%$ \\
\hline
\end{tabular}

From an overall perspective, only $11.3 \%$ students think that teacher's emphasis is teaching grammar and translation with the traditional teaching mode. $26.3 \%$ students probably agree that teacher is emphasizing subject content rather than grammar and translation in this new teaching mode. 56.2\% students agree with that and $6.2 \%$ students go all the way with that. The survey results enunciate that about $90 \%$ students agree that teacher prefer subject content to traditional teaching mode.

(3) The advantage of CBI mode

\begin{tabular}{|l|l|l|l|l|}
\hline Options & A & B & C & D \\
\hline Percentage & $13.4 \%$ & $35.1 \%$ & $47.4 \%$ & $4.1 \%$ \\
\hline
\end{tabular}

To this question only $13.4 \%$ students' answers are no, $35.1 \%$ students think that is possible they will get high marks under this new mode, $47.4 \%$ students agree with that, and $4.1 \%$ students are in full agreement to that. The research shows that students look forward to carrying out this teaching mode, and they are eager for a new way to be educated, the reason why they say yes to this question is that the traditional teaching mode no longer meets their needs for English study in the $21^{\text {st }}$ century.

(4) Students' quality

\begin{tabular}{|l|l|l|l|l|}
\hline Options & A & B & C & D \\
\hline Percentage & $5.7 \%$ & $37.6 \%$ & $41.2 \%$ & $15.5 \%$ \\
\hline
\end{tabular}

According to the above table, 5.7\% students can't accept the whole teaching of English under CBI mode. $37.6 \%$ students just want to have a try, and they do not know whether they can accept this teaching mode or they have the 
quality to accept the whole teaching of English or not, $41.2 \%$ students can accept this teaching style, $15.5 \%$ students are interested in this style.

It shows that, on the one hand, the students had already have a certain English basis, which can meet the basic requirements of CBI teaching mode; on the other hand, students' English level are uneven, and this needs to be fully considered when the teachers have different students, who should be taught in accordance with their aptitude.

(5) CBI mode can improve the comprehensive language ability to learn English?

\begin{tabular}{|l|l|l|l|l|}
\hline Options & A & B & C & D \\
\hline Percentage & $10.3 \%$ & $38.1 \%$ & $40.2 \%$ & $16.5 \%$ \\
\hline
\end{tabular}

From an overall perspective, $10.3 \%$ students think that this teaching mode can't improve their comprehensive language ability. $38.1 \%$ students are not quite sure about it. $40.2 \%$ students feel this new teaching mode can improve their comprehensive language ability, and $16.5 \%$ students consider they are bound to benefit from this new teaching mode.

This result implies that half of the students think CBI mode can improve their comprehensive language abilities.

(6)The content of CBI teaching mode related to our life can stimulate your interest in learning English?

\begin{tabular}{|l|l|l|l|l|}
\hline Options & A & B & C & D \\
\hline Percentage & $4.6 \%$ & $39.7 \%$ & $44.3 \%$ & $11.3 \%$ \\
\hline
\end{tabular}

About whether it can stimulate the students' interest in learning English, 55.6\% of the surveyed students choose "yes" or "definitely", $39.7 \%$ of the students choose "maybe", only less than $5 \%$ of the students said "no". The research shows that most people think that CBI teaching mode can stimulate their interest in learning English, for the implementation of this teaching mode laid a good foundation.

(7) Will CBI teaching mode help to broaden your social knowledge about western countries?

\begin{tabular}{|l|l|l|l|l|}
\hline Options & A & B & C & D \\
\hline Percentage & $6.2 \%$ & $34.5 \%$ & $54.1 \%$ & $5.2 \%$ \\
\hline
\end{tabular}

For question $6,59.3 \%$ of the students believe that CBI teaching mode will help to broaden their social knowledge about western countries. $34.5 \%$ of the students said "maybe", only $6.2 \%$ of the students choose "no". It shows that the traditional teaching mode can't satisfy the student's requirements to the knowledge of social country. In this new teaching mode, they will get abundant knowledge what they want; they will be more and more knowledgeable.

(8) Teachers' quality

\begin{tabular}{|l|l|l|l|l|}
\hline Options & A & B & C & D \\
\hline Percentage & $7.7 \%$ & $38.7 \%$ & $45.9 \%$ & $7.7 \%$ \\
\hline
\end{tabular}

About question 7, 53.6\% of the students think college English teachers in WTU can be qualified for the task if implementing the CBI teaching mode in our university. $38.7 \%$ of the students are not clear about that situation, and $7.7 \%$ of the students disagree. The data here show that half of the students have basically recognized the teachers' English level, but the teachers' English quality remains to be continued to improve.

(9) Students' English level

\begin{tabular}{|l|l|l|l|l|}
\hline Options & A & B & C & D \\
\hline Percentage & $23.7 \%$ & $36.6 \%$ & $31.4 \%$ & $8.2 \%$ \\
\hline
\end{tabular}

About question 9, a private question about the students' English level, 23.7\% of the students haven't passed them, $36.6 \%$ of the students haven't taken CET4 and CET6 examinations, $31.4 \%$ of the students have passed CET4, and $8.2 \%$ of the students have passed CET6.

Survey results show that the percentage of students who have passed CET4 and CET6 is not high, the reason is that the students being surveyed are all freshmen and sophomores, and freshmen haven't take these examinations.

(10) Students' interests

\begin{tabular}{|l|l|l|l|l|}
\hline Options & A & B & C & D \\
\hline Percentage & $20.6 \%$ & $31.4 \%$ & $43.3 \%$ & $4.6 \%$ \\
\hline
\end{tabular}

About the interest in learning English, in the last question, $43.3 \%$ of surveyed students have interest, $4.6 \%$ of the students have strong interest in English learning, 31.4\% of the students said they just to complete their studies, $20.6 \%$ of the students are not interested in learning English. Students' interest in English learning has laid a good foundation for smoothly organizing and improving their English level.

According to the above survey result data analysis, we can find that, because it briefly introduces CBI in the questionnaire, a small number of students do not understand it clearly, while most of the students are very willing to accept it in college English curriculum teaching, and they also think it is feasible. They hope a class with greater 
flexibility and adaptability in the curriculum; most of them think carrying out this new teaching mode would develop their comprehensive language ability of learning English and it would broaden their knowledge; they consider that most teachers in our school have the ability to this teaching mode; most of them have had the ability to accept this teaching mode.

\section{CONCLUSION}

CBI can help learners develop their language skills for academic use, and provide them with access to new concepts through meaningful content (Crandall, 1999). CBI fits in well with broader principles of language teaching and learning, and it can be applied in various situations. It could be used effectively in ESL as well as EFL classrooms (Grebe \& Stroller, 1997).

At present, WTU has made teaching reform preparations, for example we have started an advanced course in English for those students, whose English comprehensive ability are very good, and get good marks in CET4 and CET6. Besides, WTU has started oral English concentrating program. Fortunately, most of them became the translators of some organizations and occasions, such as EC, UNCTD (stationed in China) and the Asian Basketball Championship, their outstanding performances win the applause of the foreign friends.

The survey results are fairly satisfied for the author to carry out the CBI program at WTU, though it is not perfect. Because it just very briefly introduces CBI in the questionnaire, a small number of students do not understand it clearly, while most of the students are very willing to accept it in college English curriculum teaching, and they also think it is feasible. Our university has made some trials, and students are interested it and eager for it. So it is possible to apply CBI mode to our college English class in the future at WTU.

\section{Appendix 1. The Possibility Questionnaire Survey of Applying CBI to College English Teaching In OuR UNIVERSITY}

Dear students:

This questionnaire is to survey whether it is suitable to apply the Content-based Instruction (CBI) to our College English teaching for the future at WTU. Please give the true answer. This questionnaire only uses for research and do not relate with your college English final grade.

This questionnaire is divided into two parts, the first part is the introduction to CBI, and the second part is your choices based on your understanding of the first part.

\section{Thanks for your cooperation!}

School:

Major Class:

Gender:

\section{Part I:}

CBI teaching concept lies in language teaching based on a subject teaching or some kind of theme teaching. It is a second language teaching mode, in which theme content or academic content completely merge with content of language teaching activity. In brief, through the study of native English national culture and history, geography and culture to understand the foreign countries in College English course, at the same time to improve our English comprehensive abilities, and eventually improve the educational insult.

Part II:

1. Do you understand what $\mathrm{CBI}$ is after reading the above introduction?
A. no
B. basically clear
C. yes
D. definitely clear

2. Teacher's emphasis is on teaching subject content, not on grammar and translating. Do you agree?
A. no
B. basically agree
C. yes
D. definitely agree

3. Do you think that you will achieve the best in CBI English class?
A. no
B. basically agree
C. yes
D. definitely agree

4. Can you accept the whole teaching of English under CBI mode?
A. no
B. just a try
C. yes
D. eager for it

5. Do you think that carrying out this teaching mode can improve the comprehensive ability to learn English?
A. no
B. maybe
C. yes
D. definitely

6. The content of CBI mode is related to your life; do you think it can stimulate your interest in learning English?
A. no
B. maybe
C. yes
D. definitely

7. Will CBI mode help to broaden your social knowledge about foreign countries?
A. no
B. maybe
C. yes
D. definitely

8. Do you think college English teachers in our school are qualified for the task if implementing CBI mode in WTU?
A. no
B. not clear
C. maybe
D. yes

9. Have you passed CET4 and CET6?
A. no
B. not attending it
C. TEM4
D. TEM6

10. Are you interested in English learning now? 

A. no
B. complete studies
C. interest
D. keen interest

APPENDiX 2. QUESTIONNAIRE SURVEY RESUlts

\begin{tabular}{|l|l|l|l|l|}
\hline Questions & Frequency (N=194) & B & C & D \\
\hline Options & A & $35.1 \%(68)$ & $38.7 \%(75)$ & $6.7 \%(13)$ \\
\hline 1 & $19.6 \%(38)$ & $26.3 \%(51)$ & $56.2 \%(109)$ & $6.2 \%(12)$ \\
\hline 2 & $11.3 \%(22)$ & $35.1 \%(68)$ & $47.4 \%(92)$ & $4.1 \%(8)$ \\
\hline 3 & $13.4 \%(26)$ & $37.6 \%(73)$ & $41.2 \%(80)$ & $15.5 \%(30)$ \\
\hline 4 & $5.7 \%(11)$ & $38.1 \%(74)$ & $40.2 \%(78)$ & $16.5 \%(32)$ \\
\hline 5 & $10.3 \%(20)$ & $39.7 \%(77)$ & $44.3 \%(86)$ & $11.3 \%(22)$ \\
\hline 6 & $4.6 \%(9)$ & $34.5 \%(67)$ & $54.1 \%(105)$ & $5.2 \%(10)$ \\
\hline 7 & $6.2 \%(12)$ & $38.7 \%(75)$ & $45.9 \%(89)$ & $7.7 \%(15)$ \\
\hline 8 & $7.7 \%(15)$ & $36.6 \%(71)$ & $31.4 \%(61)$ & $8.2 \%(16)$ \\
\hline 9 & $23.7 \%(46)$ & $31.4 \%(61)$ & $43.3 \%(84)$ & $4.6 \%(9)$ \\
\hline 10 & $20.6 \%(40)$ & & \\
\hline
\end{tabular}

\section{REFERENCES}

[1] Adamson, H.D. (1993). Academic Competence Theory and Classroom Practice: Preparing ESL Students for Content Courses. New York: Longman.

[2] Brinton, D., Snow, M., \& Wesche, M. (1989). Content-Based Second Language Instruction. Boston: Henley and Heine.

[3] Brinton, D., Snow, M., \& Wesche, M. (2003). The content-based second language instruction. Ann Arbor: The University of Michigan Press.

[4] Brown, H. (2007). Principles of language learning and teaching. White Plains, NY: Pearson Longman.

[5] Butler, Y. (2005). Content-based instruction in EFL contexts: Considerations for effective implementation. JALT Journal 27.2, 227-245.

[6] Canagarajah, S. (2011). Code meshing in academic writing: Identifying teachable strategies of translanguaging. The Modern Language Journal 95.3, 401-417.

[7] Cai, J. (2002). Second Language Acquisition and CBI Mode. Journal of Beijing International Studies University 109.3, 13-15.

[8] Crandall, J. (1999). Content-based instruction (CBI). Concise encyclopedia of educational linguistics. Oxford, UK: Cambridge University Press.

[9] Dai, Q. \& Y. Lv. (2004). CBI Concept and Its Teaching Mode. Foreign Language Teaching Abroad, 4:16-20.

[10] Davies, S. (2006). Content based instruction in EFL contexts. The Internet TESL Journal, 2:9.

[11] Grebe, W. \& Stroller, F. (1997). Content-based instruction: research foundations. In Snow, M. Brinton (Eds.), the Content-Based Classroom: Perspectives on Integrating Language and Content. New York, 13-21.

[12] Kristen, S. D. (1982). Principles and Practice in Second Language Acquisition-Language Teaching Methodology Series. New York: Pergamum Press.

[13] Li, J. (2002). ESL Learning Strategy in China: A Case Study. Foreign Language Education, 1: 42-49.

[14] Li, Y. (2009). CBI in College English Teaching. Journal of Hetao University, 3:79-83.

[15] Luo Q. (2006). CLIL and Its Implications for China's EFL Teaching. Journal of Beijing University of Aeronautics and Astronautics (Social Sciences Edition) . 19.3, 70-72.

[16] Richards, J. \& Rodgers, T. (2001). Approaches and methods in language teaching. New York: Cambridge University Press.

[17] Shu, D. \& Zhuang Z. (1996). Modern Foreign Language Teaching Theory and Practice. Shanghai: Shanghai Foreign Language Education Press.

[18] Snow, M., \& Brinton, D. (1989). Content-based language instruction: Investigating the effectiveness of the adjunct model. TESOL Quarterly, 4,553-574.

[19] Stoller, F. (2004). Content-based instruction: Perspectives on curriculum planning. Annual Review of Applied Linguistics 24.1, 261-283.

[20] Stryker, S., \& Leaver, B. (1997). Content-based instruction in foreign language education. Washington, D.C.: Georgetown University Press.

[21] Yu, L. \& D. Yuan. (2005). Bilingual instruction and the reform of university English education. Journal of Higher Education, 26.3, 74-78.

[22] Yuan, P. (2006). The Rational and Prototype Models of Content-Based Foreign Language Teaching. Academic Degrees \& Graduate Education. 3,31-36.

[23] Zhang, Y. (2002). To strengthen practical English teaching and to improve college students' English comprehensive ability. China Higher Education, 8, 3-8.

Qunsheng Ke was born in Ezhou, Hubei, China in 1968. He received his MA degree in TESOL from Central China Normal University in 2004. He is currently an associate professor in the School of Foreign Languages, Wuhan Textile University, Wuhan, China. His academic research mainly focuses on applied linguistics and TEFL.

Xiaoying Chen was born in Huanggang, Hubei, China in 1974. She is an English teacher in Taihe High School, Ezhou, Hubei. Her interest is EFL teaching research. 